\title{
Long-term outcome of porcine skin graft in surgical treatment of recurrent pelvic organ prolapse. An open randomized controlled multicenter study
}

Eva Dahlgren and Preben Kjölhede

\section{Linköping University Post Print}

N.B.: When citing this work, cite the original article.

This is the authors' version of the following article:

Eva Dahlgren and Preben Kjölhede, Long-term outcome of porcine skin graft in surgical treatment of recurrent pelvic organ prolapse. An open randomized controlled multicenter study, 2011, Acta Obstetricia et Gynecologica Scandinavica, (90), 12, 1393-1401.

which has been published in final form at:

http://dx.doi.org/10.1111/j.1600-0412.2011.01270.x

Copyright: Informa Healthcare / Wiley-Blackwell

http://eu.wiley.com/WileyCDA/Brand/id-35.html

Postprint available at: Linköping University Electronic Press

http://urn.kb.se/resolve?urn=urn:nbn:se:liu:diva-73323 
Main research article with the title

Long-term outcome of porcine skin graft in surgical treatment of recurrent pelvic organ prolapse. An open randomized controlled multicenter study.

Eva Dahlgren ${ }^{1}, \mathrm{MD}, \mathrm{PhD}$ and Preben $\underline{\text { Kjølhede }}^{2}, \mathrm{MD}, \mathrm{PhD}$; on behalf of the RPOP-PELVICOL Study Group*

${ }^{1}$ Department of Obstetrics and Gynecology, Institute of Clinical Sciences, Sahlgrenska Academy, Gothenburg University, Gothenburg, Sweden

${ }^{2}$ Division of Obstetrics and Gynecology, Department of Clinical and Experimental Medicine, Faculty of Health Sciences, Linköping University, Department of Obstetrics and Gynecology, County Council of Östergötland, Linköping, Sweden

Corresponding author:

Eva Dahlgren, MD, PhD

Department of Obstetrics and Gynecology,

Sahlgrenska University Hospital

41345 Gothenburg

Sweden

Phone +46 313421000

E-mail: Eva.Dahlgren@vgregion.se

* see Appendix for participants in the RPOP-PELVICOL Study Group. 


\begin{abstract}
Objective: To determine the long-term objective and subjective outcomes of use of a porcine skin graft (Pelvicol $\left.{ }^{\mathrm{TM}}\right)$ compared with conventional colporrhaphy in recurrent pelvic organ prolapse surgery and to analyze risk factors and safety.

Design: Open randomized controlled multicenter study.

Setting: Eight Swedish hospitals.
\end{abstract}

Population: 135 consecutive women with recurrent cystocele and/or rectocele admitted for vaginal prolapse surgery were randomized; 132 completed the study, 64 to conventional colporrhaphy and 68 to Pelvicol.

Methods: Conventional anterior and posterior colporrhaphy and colporrhaphy with use of Pelvicol ${ }^{\mathrm{TM}}$ mesh reinforcement. Clinical evaluation by means of Pelvic Organ Prolapse Quantification (POP-Q) and symptom questionnaire preoperatively, three months and three years postoperatively.

Main outcome measures: Anatomical and subjective outcome. Recurrence was defined as POP-Q $\geq$ stage 2 .

Results: At 3-month follow-up early recurrence/surgical failures occurred significantly more often in the Pelvicol ${ }^{\mathrm{TM}}$ group, but at the 3-year follow-up the recurrence rates were similar. The recurrence rates in the anterior compartment were $57-62 \%$ and $44-23 \%$ in the posterior compartment for the colporrhaphy and Pelvicol ${ }^{\mathrm{TM}}$ groups, respectively. Symptoms were substantially and equally reduced in the two groups after surgery. Sexual activity and function did not seem to be affected adversely in any group. The complication rate was low. Risk factors for anatomical recurrence were age, body mass index and preoperative stage of the prolapse.

Conclusions: Use of Pelvicol ${ }^{\mathrm{TM}}$ did not provide advantages to conventional colporrhaphy in recurrent pelvic organ prolapse concerning anatomical and subjective outcomes with the surgical technique used in this study. 


\section{Key words}

Colporrhaphy; Outcome; Pelvicol; Randomized study; Recurrent prolapse

$\begin{array}{lll}\text { Abbreviations } \\ \mathrm{CCG} & =\text { conventional colporrhaphy group } \\ \mathrm{CI} & =\text { confidence interval } \\ \mathrm{OR} & =\text { odds ratio } \\ \mathrm{PG} & =\text { Pelvicol implant group } \\ \mathrm{POP} & = & \text { Pelvic Organ Prolapse } \\ \text { POP-Q } & = & \text { Pelvic Organ Prolapse Quantification } \\ \text { SUI } & = & \text { Stress urinary incontinence }\end{array}$




\section{Introduction}

Pelvic organ prolapse (POP) is a common condition in women (1). The annual age-related incidence of surgery for POP is in the range of 10 to 30 per 10000 women (2). Surgical management should aim to provide the most durable repair. The objective outcomes of primary POP surgery vary depending on the site of surgery and the stage of the prolapse. Recurrence rates up to $40-50 \%$ have been reported (2,3). Although recurrent prolapse occurs in a substantial proportion of women operated for POP it seems that only a smaller proportion of these undergo reoperation (3-5). Treatment of recurrent POP is a challenge to the medical community. It is the general clinical impression among gynecologists that the outcome of surgical treatment of recurrent POP with traditional vaginal prolapse surgery is usually less favorable than the outcome after primary surgery. However, the outcome of surgery for recurrent POP has not been well investigated and the results to date are ambiguous $(6,7)$. In the Cochrane review of surgical management of pelvic organ prolapse (1) data concerning operations for recurrent POP have not been specifically presented but have been pooled with the data of primary operations.

The use of meshes in prolapse surgery evolved during the late 1990's, probably mostly due to reports of the high cure rate with use of meshes in hernia repair but also due to the reports of high recurrence rates after conventional vaginal prolapse surgery. Several types of graft material, - synthetic and biologic; non-absorbable and absorbable; auto-, allo- or xenografts, have been used (8). The results have been contradictory and recommendations for the use of meshes in POP surgery vary (9). The synthetic meshes seemed to exhibit a high risk of complications in particular with mesh erosions (10). This side-effect seemed to be significantly less pronounced when using biologic meshes. Thus biologic grafts were considered to be more ideal in POP surgery. Pelvicol ${ }^{\mathrm{TM}}$ is a biologic xenograft acellular collagen matrix. It consists of sterile, biocompatible, cross-linked porcine dermal collagen that readily incorporates into host tissue. When Pelvicol ${ }^{\mathrm{TM}}$ was introduced in Sweden in 2000 we found it of interest to use this graft in the surgical treatment of recurrent POP. The women with recurrent POP were chosen basically because of the lack of randomized studies on Pelvicol $^{\mathrm{TM}}$ in prolapse surgery and a presumed higher efficacy of the mesh on objective outcome measures after reoperation for POP. Besides, from an ethical point of view it seemed acceptable to use reinforcement material in this group of women since conventional treatment had already failed, and a new operation with the conventional technique could be anticipated to give an outcome less favorable than that of the primary operation. 
The objectives of this randomized, open, controlled multicenter study were to determine the long-term effectiveness of use of the Pelvicol ${ }^{\mathrm{TM}}$ graft in recurrent POP surgery by means of objective and subjective measures and to analyze risk factors and complication rates. We hypothesized that use of Pelvicol ${ }^{\mathrm{TM}}$ graft to augment the native fascial structures in POP would improve the objective and subjective outcome compared with use of traditional colporrhaphy in surgery for recurrent POP. 


\section{Material and methods}

An open randomized controlled multicenter study was conducted comparing conventional colporrhaphy with vaginal repair using porcine dermal implant in women with recurrent POP. Eight Swedish hospitals participated. Women who were admitted to the departments of obstetrics and gynecology in these hospitals for surgical treatment of recurrent POP in the anterior and/or posterior vaginal compartment were eligible. Recurrent POP was defined as a relapse in a site previously operated upon for prolapse. The study was approved by the ethical research committees of Gothenburg University, Örebro University and Linköping University.

The study was performed between November 2003 and April 2010. Sample size was based on the assumption that a 15\% difference in objective cure rate after three years between the implant-augmented repair and the traditional anterior/posterior colporrhaphy with $90 \%$ power should be significant at a 5\%-level. It was estimated that totally 160 women, 80 in each arm, including a drop-out of $10 \%$, were needed.

Randomization was carried out as a block randomization. A computer generated the randomization sequences into blocks of 10 with equal number of the two modes of surgery for each of the eight participating centers. The allocated mode of surgery was written on a label that was sealed in opaque consecutively numbered envelopes. The centers were assigned one to three blocks corresponding to the expected number of eligible patients at the hospital.

The women were required to give informed written consent before entering into the study. At each center the envelopes were opened in consecutive number order of patient inclusion before start of surgery in the operating theatre. The participant received information about the allocated mode of surgery after the surgery.

The prolapse was evaluated by means of the pelvic organ prolapse quantification system (POP-Q) (11) preoperatively, three months and three years postoperatively. The pelvic examination was conducted in the lithotomy position. For the purpose of this study only points $\mathrm{Ba}$ and $\mathrm{Bp}$ are presented. Objective anatomically cure was defined as POP-Q less than stage 2 in the compartment operated upon. Women who had a relapse of the prolapse after the operation in the study and underwent additional POP surgery during the follow-up period were not followed further, according to the study protocol. In the analyses of the objective outcomes three years after surgery, the POP-Q status evaluated immediately prior to the relapse surgery was used as a substitute for the otherwise lacking measurements at the 3-year follow-up. 
In order to assess symptoms the women completed a questionnaire deriving from the validated questionnaire by Mouritsen et al. (12) encompassing questions covering vaginal, urinary and anorectal symptoms and sexual issues. The questions were constructed as simple sentences and the answers were given by placing a cross next to the written alternatives indicating the frequency of occurrence of the symptom or condition.

Surgery was intended to be carried out following standardized procedures. To achieve maximal agreement on surgical technique the participating surgeons met at two workshops before the start of the study. It was allowed to plicate the levator ani muscles and to perform a perineoplasty if the attachments to the perineal body peroperatively were found to be disrupted and if the perineal body was deficient. Apical support was to be secured, if needed, either by fixing the vaginal apex to the sacrouterine ligaments or to the sacrospinous ligament. In case of overt stress urinary incontinence the surgeon was allowed, but was not required, to perform an incontinence operation simultaneously with the prolapse operation. Mode of anesthesia was left to the discretion of the surgeon and anesthesiologist.

The conventional anterior and posterior colporrhaphies were performed according to the methods described by Thomson et al. with midline fascial plication $(13,14)$ using interrupted polydioxanon absorbable sutures. The vaginal wall was eventually closed with polyglactin 910 or Polysorb ${ }^{\mathrm{TM}}$ absorbable sutures (www.syneture.com).

When Pelvicol $^{\mathrm{TM}}$ (BARD, Norden AB, Helsingborg, Sweden) was used, the vaginal wall was opened in a similar way by midline incision. The porcine dermal implant (Pelvicol ${ }^{\mathrm{TM}}$ ) was used as an inlay covering the fascial defect between the vaginal fascial layer and the underlying cysto- or rectocele and with no other reconstructive measure. The size of the implant was adjusted in order to fit the surgical field and to be able to be anchored without tension. The implant was anchored to the vaginal and pelvic fascia with six to eight polydioxanon absorbable sutures. Finally, the vaginal wall was closed with polyglactin 910 or Polysorb ${ }^{\mathrm{TM}}$ absorbable sutures. No drainage was used.

\section{Statistical analyses}

For statistical analyses the severity of symptoms were dichotomized categorically as presence of symptom once or more per week versus less than once per week and the degree of prolapse as prolapse less than stage 2 or stage 2 or more.

Data are presented as number and percent or median and range. Univariate analyses were executed by means of Mann Whitney U-test for continuous data and Yates' corrected $\chi^{2}$ test and Fishers' exact test, when appropriate, for nominal data. A p $<0.05$ (two-sided) was 
considered significant. Analyses of outcome variables were done by means of multiple logistic regression models. Adjustment was done for known risk factors for prolapse and recurrence: age, number of deliveries, body mass index (BMI) and previous hysterectomy. In the objective outcome variables the preoperative stage of the prolapse was added as a confounder and in the subjective outcome parameters the preoperative occurrence of the specific symptom was included. Results are presented as odds ratios (OR's) and 95\% confidence interval (CI). The software StatView ${ }^{\circledR}$ for Windows, Copyright $\odot$, 1992-1998, Version 5.0.1 (SAS Institute Inc., SAS Campus Drive, Cary, NC 27513, USA) was used for the statistical analyses. 


\section{Results}

The flow chart of the study participants is shown in Figure 1. Demographic and clinical data at baseline are presented in Table 1. Per- and postoperative data are presented in Table 2. Concomitant vaginal hysterectomy was done significantly more often in the conventional

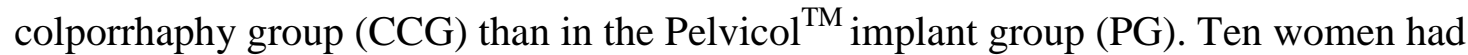
additional POP surgery $3-35$ months after the study operation, 5 in the CCG and 5 in the PG.

\section{Anatomic outcome}

The anatomically outcomes regarding recurrence of prolapse of the anterior and posterior compartments at the 3-month and 3-year follow-up are shown in Table 3. Significantly more women in the PG had early recurrence/surgical failures at the 3-month follow-up in the anterior compartment than in the CCG but at the 3-year follow-up the recurrence rates had leveled out and did not differ significantly. Likewise development of de-novo prolapse components at the 3-year follow-up did not differ significantly between the CCG and PG (in the anterior compartment: $15.8 \%(3 / 19)$ vs. $5.0 \%(1 / 20)$, adjusted OR $0.26(0.02-3.32)$ and in the posterior compartment: $7.7 \%$ (2/26) vs. 11.4\% (4/35), adjusted OR 2.17 (0.33-14.29)).

Overall 58\% (38/65) of the women in the PG had recurrent prolapse three years after the operation a frequency not significantly different from the 67\% (41/61) among the women in the CCG (adjusted OR $0.70(0.33-1.48)$ ). No significant differences were seen in recurrence rates in relation to the extent of the surgery, i.e. surgery in anterior or posterior compartment only or combined anterior and posterior compartments (data not shown).

\section{Symptom outcome}

The prevalence of symptoms is shown in Figure 2. No significant differences for any of the symptoms were observed preoperatively between the two groups. The prevalence of the prolapse-related symptoms pelvic pressure and heaviness, and feeling of a vaginal lump decreased considerably after surgery. At the 3-year follow-up the feeling of a vaginal lump occurred significantly more often in women in the PG than in the CCG (adjusted OR 7.75 (1.27-47.62)) whereas no significant differences were observed between the groups as concerned prevalence of pelvic pressure and heaviness, urinary and fecal incontinence, digitations, being sexually active or dyspareunia. 


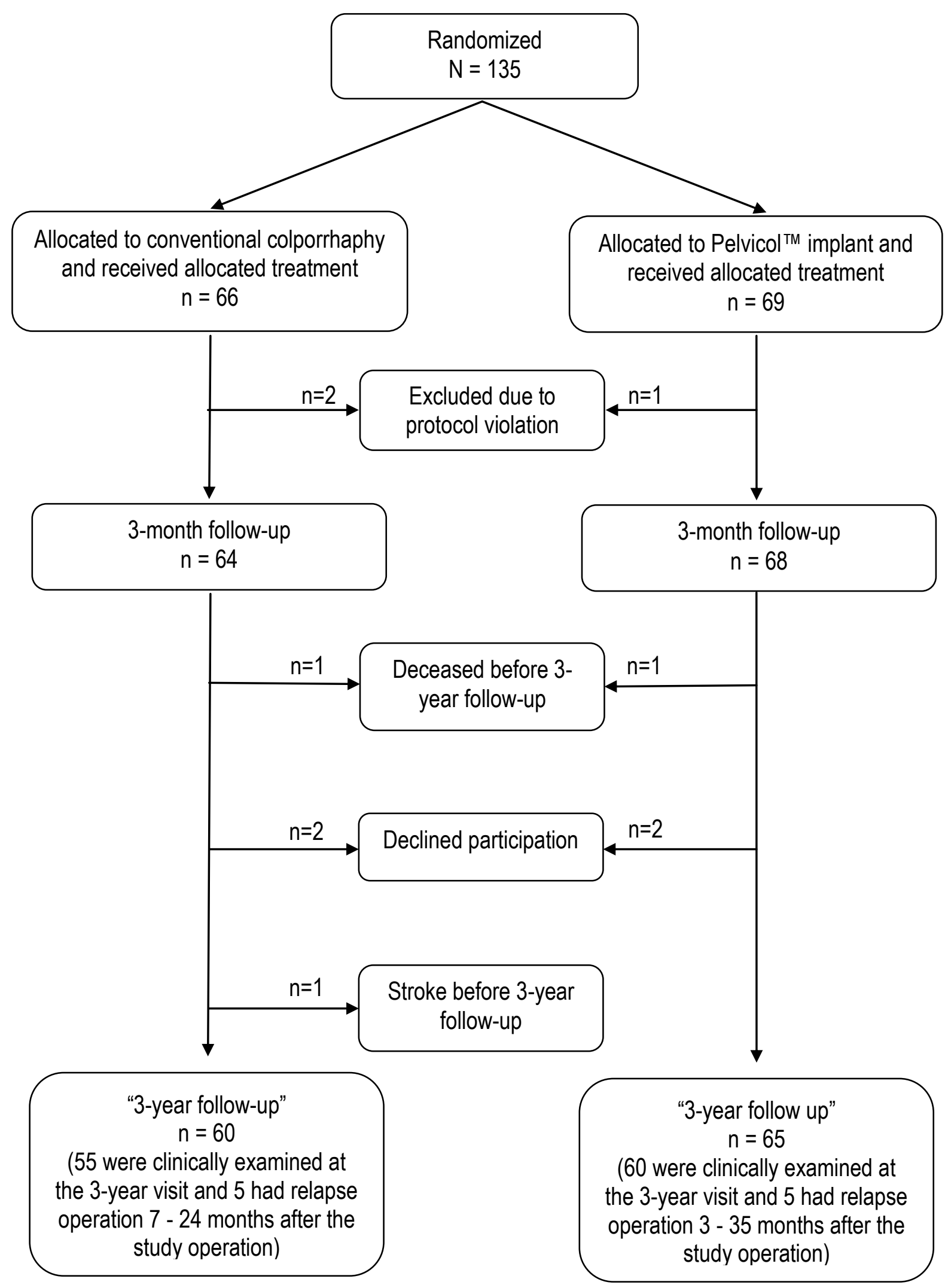

Figure 1. Flow chart of participants in the study. 


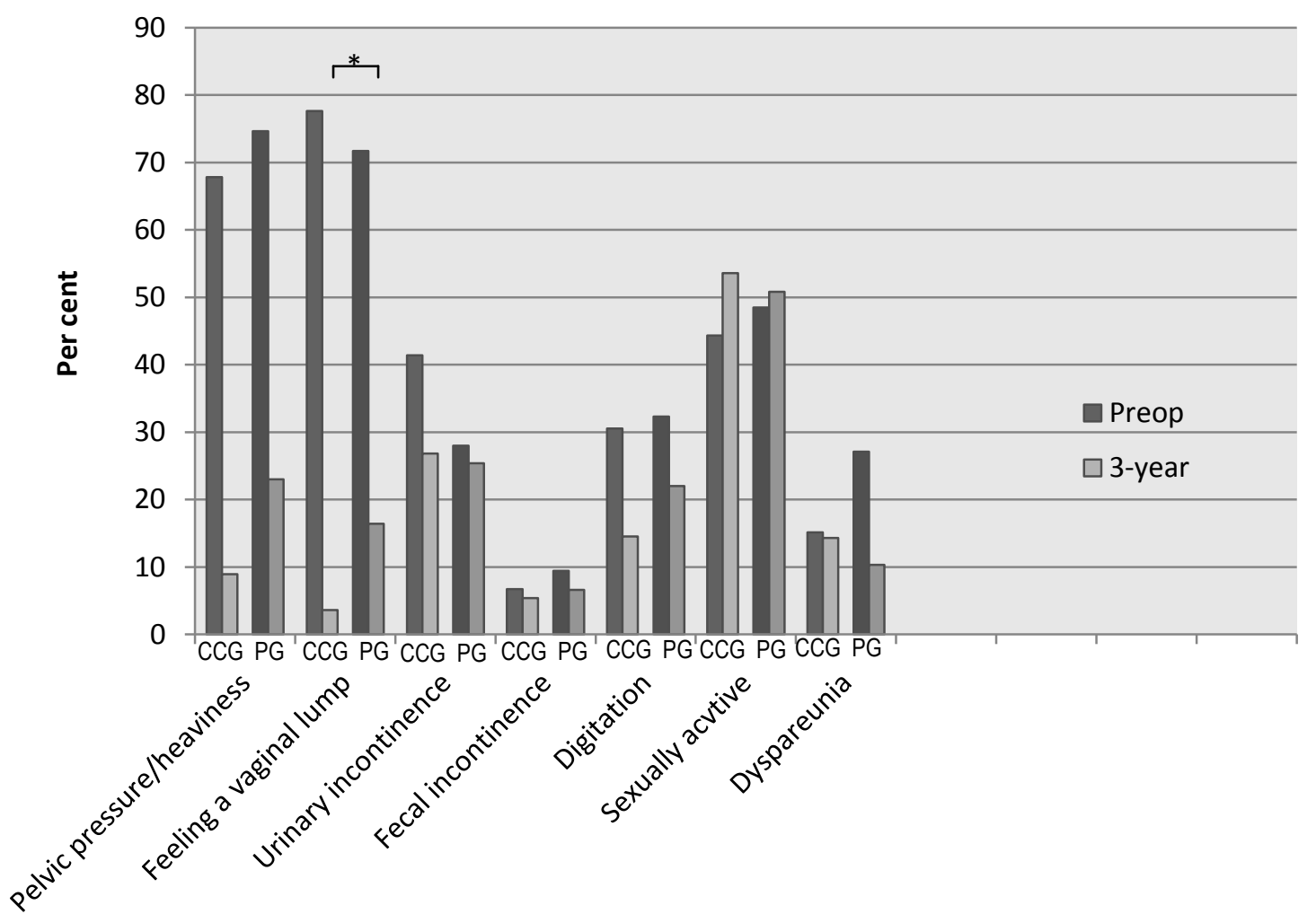

Figure 2. Prevalence of symptoms preoperatively and at the 3-year follow-up in the Conventional colporrhaphy group (CCG) and the Pelvicol ${ }^{\mathrm{TM}}$ implant group (PG). * indicates significant difference between CCG and PG,

Eighty four percent of the women in the PG and $85 \%$ in the CCG declared at the 3-year follow-up that the operation had improved or cured their pelvic symptoms.

\section{Risk factors}

Of the analyzed confounding factors used in the multiple logistic regression models, BMI was found to be an independent risk factor for feeling of a vaginal lump (OR 1.36 (1.11-1.67)), pelvic pressure and heaviness (OR 1.24 (1.05-1.45)) and not being sexually active (OR 1.27 (1.06-1.51)). Age was an independent risk factor for pelvic pressure and heaviness (OR 1.08 (1.01-1.16)), and for not being sexually active (OR 1.25 (1.13-1.38)). The preoperative stage of the prolapse and preoperative state for all the symptoms that were evaluated except pelvic pressure and heaviness and feeling a vaginal lump were strong independent risk factors with OR's ranging from 4.02 to 489.00. Experience of pelvic pressure and heaviness and feeling a 
vaginal lump three years after the operation were not associated with the corresponding symptom preoperatively.

\section{Complications}

Two women in the PG presented with minor mesh erosion (4.4\%) two weeks and three months, respectively, after the operation. These were treated conservatively and healed spontaneously. Two women in the PG and one in the CCG developed local infection postoperatively; all treated successfully with one course of antibiotics per orally. Four women in the PG and one in the CCG developed transient urinary retention postoperatively. Three women in the PG developed vaginal stenosis that was treated with dilatation in two of the cases and plastic operation in the last case. None of these three women had had perineoplasty, but plication of the levator ani muscles had been performed in one. 


\section{Discussion}

This study showed that the use of porcine dermal graft in recurrent pelvic organ prolapse surgery did not reveal superiority in objective and subjective outcomes compared with conventional colporrhaphy. It seemed that early recurrence/surgical failure was more common in women who had the porcine dermal graft, in particular in the anterior vaginal compartment, but this was made up for after three years. Prolapse symptoms decreased considerably after surgery in both groups, but the feeling of a vaginal lump was significantly more often experienced after Pelvicol ${ }^{\mathrm{TM}}$ graft implant. Complication rates were low and no serious or severe complications were seen.

This study is to the best of our knowledge the first randomized study that compares Pelvicol ${ }^{\mathrm{TM}}$ with conventional colporrhaphy in recurrent POP surgery. The strengths of the study are in addition to the randomized design the multicenter approach, which makes the results more likely to represent the general everyday work experience in the clinics. There are however, some methodological limitations. The study is open and it is therefore possible that the patient's knowledge of the method used could bias the subjective outcomes, but hardly the objective outcomes. The study material is heterogeneous concerning size and extent of prolapse. We included women with recurrent prolapse in the anterior and/or posterior compartment and it may therefore be more difficult to interpret the results. However, due to the fact that only a selected group of women with recurrent POP was admitted for recurrent surgery it was difficult to obtain a homogenous population concerning size and extent of prolapse of sufficient size in a reasonable time span.

Recruitment of the planned number of women was anticipated to take two years. Due to a much lower number of patients admitted to the clinics with recurrent prolapse than anticipated we decided to close the recruitment after four years of inclusion. At that time 135 women were included in the study. Prior to this decision we considered to include more centers in the study in order to obtain the planned number of patients in the study. However, it was not practically possible to do this since new devices with synthetic meshes in prolapse surgery (as for instance Gynecare Prolift ${ }^{\mathrm{TM}}$, www.ethicon360.com) had been introduced and gained wide acceptance among urogynecologists during the study period. We were as result not able to reach the estimated power of $90 \%$ in the study. However, given the same constraints and with 130 participants the study would have had an estimated power of more than $80 \%$. The sample size estimation was based on a comparison between colporrhaphy and Pelvicol $^{\mathrm{TM}}$ graft implant. Ideally consideration in the power calculation should have been 
taken to the subgroups of combinations of surgical procedures, and size and extent of the prolapse.

A few women had a concomitant operation in a compartment that was preoperatively classified as stage $0-1$. The decision about that intervention was made by the surgeon during surgery if the prolapse was considered larger than at the preoperative examination and a weakness was found in the compartment and the patient simultaneously had symptoms.

Vaginal hysterectomy was executed significantly more often in the CCG compared with the PG. This probably reflects a selection bias. The surgeons might be more prone to avoid the more extensive surgery and thereby increased risks of infection when an implant was to be put in place.

Since we started the study two randomized studies have been published presenting results of primary POP surgery comparing traditional colporrhaphy with Pelvicol ${ }^{\mathrm{TM}}$ reinforcement $(15,16)$. The results of these two studies were contradictory. One of the studies reported a benefit in anatomical outcome after Pelvicol (15) whereas in the other no difference in anatomical outcome was found (16). However, the surgical technique differed significantly concerning the Pelvicol group which may explain in whole or in part the different outcomes. Meschia et al. plicated the vaginal fascia before applying and anchoring the Pelvicol ${ }^{\mathrm{TM}}$ mesh (15) whereas Hvid et al. refrained from this and anchored the graft laterally to the pubocervical fascia and distally to the cardinal ligament/cervix (16). Thus in the former study the mesh was used as a support in an anterior colporrhaphy whereas in the latter it was used as a substitute for a defective fascia, i.e. as a direct hammock. In the present study we used a similar technique as that described by Hvid et al.. Whether the technique described by Mechia et al (15) using the PelvicolTM as an support of a colporrhaphy also would be superior to conventional colporrhaphy in recurrent POP surgery is not known.

The recurrence rates after primary surgery with use of Pelvicol vary from 7- $46 \%$. (1519). In the present study the anatomical recurrence rates in the anterior and posterior compartments were high in both groups; $57-62 \%$ in the anterior compartment and $17-40 \%$ in the posterior compartment. However, the recurrence rates vary between $28-70 \%$ (20-23) after primary prolapse surgery with anterior colporrhaphy and after posterior colporrhaphy in 8-24\% (20,22,24-26). Recently, Peterson et al. presented a retrospective case-control study of recurrent prolapse surgery with anterior colporrhaphy showing a recurrence rate of cystocele of $57 \%$ compared with $29 \%$ for women with primary surgery (6). The reason for the high recurrence rate in anatomical outcomes in our study is most likely multifactorial with a combination of surgical related and pathophysiological factors as main causes. 
Symptoms related to prolapse were reduced substantially by the surgery, independent of mode of surgery, in spite of a high anatomically recurrence rate. It is well known that there are disagreements between stage and symptoms of prolapse $(27,28)$. Miedel et al. found a high anatomical recurrence rate but less than one-fourth of the women with recurrence were symptomatic (22). Tegerstedt et al. stated that an unsatisfactory anatomic outcome of prolapse surgery was not necessarily associated with symptoms (3). Our study seemed to support this. The reason for the discrepancy in anatomical outcome and symptoms is still unknown. In accordance with other studies sexual life did not seem to be influenced negatively by use of Pelvicol $(15,17,26)$. Besides, the women who had conventional colporrhaphy did not seem to be adversely affected in sexual activity either. This is in accordance with the findings by Abramov et al. (25) and probably reflects restricted use of levator ani muscle plication.

The analyses showed that age, BMI and POP stage were risk factors for a poor outcome of recurrent POP surgery. These factors are all known risk factors even in primary POP surgery and seem to be factors reflecting systemic pathophysiological conditions for developing pelvic floor insufficiency (29). How the risk factors can be used as preventive measures, i.e. to obtain better outcome after primary as well as recurrent prolapse surgery, is still unclear. Should obese women with POP undergo weight reduction prior to surgery? Or should women with POP be advised to undergo surgery at a lower age before the symptoms becomes too severe or the prolapse becomes too large? These questions need to be addressed in well conducted studies.

The complication rate was low after use of Pelvicol ${ }^{\mathrm{TM}}$. In particular troublesome mesh erosion was not seen and no rejection of the implant occurred which is in accordance with findings presented by others $(15,16,18,19)$.

In conclusion, PelvicolTM does not seem to improve anatomical or subjective outcomes more than traditional colporrhaphy in recurrent POP surgery with the surgical technique used in this study. The results of this study illustrate and emphasize the importance of scientific evaluation before new surgical methods are introduced in clinical practice. More studies are needed using biomesh, - Pelvicol ${ }^{\mathrm{TM}}$ or others, as reinforcement after suturing of existing fascia defects and with more focus on standardization of surgical technique and directly comparable treatment arms by surgical procedure. 


\section{Acknowledgements}

We are grateful to the physicians and research nurses in the study group for their work and support.

\section{Funding}

The study was financially supported by grants from the Health \& Medical Care Committee of the Regional Executive Board, Region Västra Götaland and from the Medical Research Council of South East Sweden; Linköping University and the County Council of Östergötland. 
Pelvicol in recurrent POP surgery

\section{Disclosure of Interests}

None of the authors or "RPOP-Pelvicol Study Group" members has any conflicts of interest to declare. 


\section{References}

1. Maher C, Baessler K, Glazener CM, Adams EJ, Hagen S. Surgical management of pelvic organ prolapse in women. Cochrane Database Syst Rev. 2007 Jul 18;(3):CD004014.

2. Brubaker L, Bump R, Jacquetin B, Schuessler B, Weidner A, Zimmern P, et al. Pelvic organ prolapse. In: Incontinence: $2^{\text {nd }}$ International Consultation on Incontinence July 1 3, 2001. Eds. Abrams P, Cardozo L, Khoury S, Wein A. $2^{\text {nd }}$ Edition. Health Publication Ltd, Plymouth, United Kingdom. 2002:243-65.

3. Tegerstedt G, Hammarström M. Operation for pelvic organ prolapse: a follow-up study. Acta Obstet Gynecol Scand. 2004;83(8):758-63.

4. Moghimi K, Valbø A. Genital prolapse: a follow-up study assessing subjective and objective results five years or more after surgical intervention. Eur J Obstet Gynecol Reprod Biol. 2005;120(2):198-201.

5. Crafoord K, Sydsjö A, Kjølhede P. Genital prolapse surgery after a shift in treatment tradition: an analysis of subsequent prolapse surgery. Acta Obstet Gynecol Scand. 2008;87(4):449-56.

6. Peterson TV, Karp DR, Aguilar VC, Davila GW Primary versus recurrent prolapse surgery: differences in outcomes. Int Urogynecol J Pelvic Floor Dysfunct. 2010;21(4):483-8.

7. Sand PK, Koduri S, Lobel RW, Winkler HA, Tomezsko J, Culligan PJ, et al. Prospective randomized trial of polyglactin 910 mesh to prevent recurrence of cystoceles and rectoceles. Am J Obstet Gynecol. 2001;184(7):1357-62.

8. Griffis K, Hale DS. Grafts in pelvic reconstructive surgery. Clin Obstet Gynecol. 2005;48(3):713-23.

9. Jia X, Glazener C, Mowatt G, MacLennan G, Bain C, Fraser C, et al. Efficacy and safety of using mesh or grafts in surgery for anterior and/or posterior vaginal wall prolapse: systematic review and meta-analysis. BJOG. 2008;115(11):1350-61.

10. Milani R, Salvatore S, Soligo M, Pifarotti P, Meschia M, Cortese M. Functional and anatomical outcome of anterior and posterior vaginal prolapse repair with prolene mesh. BJOG. 2005;112(1):107-11.

11. Bump RC, Mattiasson A, Bo K, Brubaker LP, DeLancey JO, Klarskov P, et al. The standardization of terminology of female pelvic organ prolapse and pelvic floor dysfunction. Am J Obstet Gynecol 1996;175:10-7. 
12. Mouritsen L, Larsen JP. Symptoms, bother and POPQ in women referred with pelvic organ prolapse. Int Urogynecol J Pelvic Floor Dysfunct. 2003;14(2):122-7.

13. Thomson J. Lewis Wall L, Growdon WA, Ridley JH. Urinary incontinence. In: Thomson J, Rock J, editors. Te Lindes’s Operative Gynecology. 7th edn. Philadelphia. J.B. Lippincott Company, 1992. 904-14.

14. Thomson J. Relaxed vaginal outlet, rectocele, fecal incontinence, and rectovaginal fistula. In: Thomson J, Rock J, editors. Te Lindes's Operative Gynecology. 7th edn. Philadelphia. J.B. Lippincott Company, 1992. 945-53.

15. Meschia M, Pifarotti P, Bernasconi F, Magatti F, Riva D, Kocjancic E. Porcine skin collagen implants to prevent anterior vaginal wall prolapse recurrence: a multicenter, randomized study. J Urol. 2007;177(1):192-5.

16. Hviid U, Hviid TV, Rudnicki M. Porcine skin collagen implants for anterior vaginal wall prolapse: a randomised prospective controlled study. Int Urogynecol J Pelvic Floor Dysfunct. 2010;21(5):529-34.

17. Handel LN, Frenkl TL, Kim YH. Results of cystocele repair: a comparison of traditional anterior colporrhaphy, polypropylene mesh and porcine dermis. J Urol. 2007;178(1):153-6.

18. Natale F, La Penna C, Padoa A, Agostini M, De Simone E, Cervigni M. A prospective, randomized, controlled study comparing Gynemesh, a synthetic mesh, and Pelvicol, a biologic graft, in the surgical treatment of recurrent cystocele. Int Urogynecol J Pelvic Floor Dysfunct. 2009;20(1):75-81.

19. de Boer TA, Gietelink DA, Hendriks JC, Vierhout ME. Factors influencing success of pelvic organ prolapse repair using porcine dermal implant Pelvicol. Eur J Obstet Gynecol Reprod Biol. 2010;149(1):112-6.

20. Sand PK, Koduri S, Lobel RW, Winkler HA, Tomezsko J, Culligan PJ, et al. Prospective randomized trial of polyglactin 910 mesh to prevent recurrence of cystoceles and rectoceles. Am J Obstet Gynecol. 2001;184(7):1357-62

21. Weber AM, Walters MD, Piedmonte MR, Ballard LA. Anterior colporrhaphy: a randomized trial of three surgical techniques. Am J Obstet Gynecol. 2001;185(6):1299304.

22. Miedel A, Tegerstedt G, Mörlin B, Hammarström M. A 5-year prospective follow-up study of vaginal surgery for pelvic organ prolapse. Int Urogynecol J Pelvic Floor Dysfunct. 2008;19(12):1593-601. 
23. Nieminen K, Hiltunen R, Takala T, Heiskanen E, Merikari M, Niemi K, et al. Outcomes after anterior vaginal wall repair with mesh: a randomized, controlled trial with a 3 year follow-up. Am J Obstet Gynecol. 2010;203(3):235.e1-8.

24. Kahn MA, Stanton SL. Posterior colporrhaphy: its effects on bowel and sexual function. Br J Obstet Gynaecol. 1997;104(1):82-6.

25. Abramov Y, Gandhi S, Goldberg RP, Botros SM, Kwon C, Sand PK. Site-specific rectocele repair compared with standard posterior colporrhaphy. Obstet Gynecol. 2005;105(2):314-8.

26. Paraiso MF, Barber MD, Muir TW, Walters MD. Rectocele repair: a randomized trial of three surgical techniques including graft augmentation. Am J Obstet Gynecol. 2006;195(6):1762-71.

27. Ellerkmann RM, Cundiff GW, Melick CF, Nihira MA, Leffler K, Bent AE. Correlation of symptoms with location and severity of pelvic organ prolapse. Am J Obstet Gynecol. 2001;185(6):1332-7.

28. Broekhuis SR, Fütterer JJ, Hendriks JC, Barentsz JO, Vierhout ME, Kluivers KB. Symptoms of pelvic floor dysfunction are poorly correlated with findings on clinical examination and dynamic MR imaging of the pelvic floor. Int Urogynecol J Pelvic Floor Dysfunct. 2009;20(10):1169-74.

29. Tinelli A, Malvasi A, Rahimi S, Negro R, Vergara D, Martignago R, et al. Age-related pelvic floor modifications and prolapse risk factors in postmenopausal women. Menopause. 2010;17(1):204-12. 


\section{Legends to Tables and Figures}

Table 1. Demographic and clinical data at baseline.

Table 2. Per- and postoperative data.

Table 3. Recurrence rates three months and three years following prolapse surgery with conventional colporrhaphy (the Conventional Colporrhaphy Group (CCG)) or implant with Pelvicol $^{\mathrm{TM}}$ (the Pelvicol ${ }^{\mathrm{TM}}$ Group (PG)).

Figure 1. Flow chart of participants in the study.

Figure 2. Prevalence of symptoms preoperatively and at the 3-year follow-up in the Conventional colporrhaphy group (CCG) and the Pelvicol ${ }^{\mathrm{TM}}$ implant group (PG). * indicate significant difference between CCG and PG. 
Table 1. Demographic and clinical data at baseline.

\begin{tabular}{|c|c|c|c|c|c|}
\hline \multirow{2}{*}{$\begin{array}{l}\text { Characteristic } \\
\text { Age (years) }\end{array}$} & & \multicolumn{2}{|c|}{$\begin{array}{c}\text { Conventional } \\
\text { Colporrhaphy group } \\
n=64\end{array}$} & \multicolumn{2}{|c|}{$\begin{array}{c}\text { Pelvicol }^{\mathrm{TM}} \\
\text { implant group } \\
n=68\end{array}$} \\
\hline & & 69.0 & $41-87$ & 65.0 & $40-80$ \\
\hline \multicolumn{2}{|l|}{ BMI $\left(\mathrm{kg} / \mathrm{m}^{2}\right)$} & 25.7 & 18.7-38.1 & 25.8 & $16.2-38.3$ \\
\hline \multicolumn{2}{|l|}{ Parity } & 3.0 & $0-5$ & 2.0 & $0-6$ \\
\hline \multicolumn{2}{|l|}{ Proportion vaginal deliveries (\%) } & 100 & $50-100$ & 100 & $75-100$ \\
\hline \multicolumn{2}{|l|}{ Nulliparous (no. of women) } & 1 & $1.6 \%$ & 1 & $1.5 \%$ \\
\hline \multicolumn{2}{|l|}{ Birth weight of heaviest child $(\mathrm{kg})$} & 4.0 & $1.7-5.9$ & 4.0 & $1.8-5.5$ \\
\hline \multicolumn{2}{|l|}{ Episiotomy (no. of women) ${ }^{*}$} & 19 & $33 \%$ & 21 & $34 \%$ \\
\hline \multicolumn{2}{|c|}{ Obstetric anal sphincter rupture (no. of women) ${ }^{*}$} & 2 & $3 \%$ & 4 & $6 \%$ \\
\hline \multicolumn{2}{|c|}{ Previous hysterectomy (no. of women) } & 24 & $38 \%$ & 33 & $49 \%$ \\
\hline \multicolumn{2}{|c|}{ Previous urinary incontinence surgery (no. of women)* } & 5 & $8 \%$ & 6 & $9 \%$ \\
\hline \multicolumn{2}{|c|}{ Previous fecal incontinence surgery (no. of women) ${ }^{*}$} & 0 & $0 \%$ & 1 & $1.6 \%$ \\
\hline \multicolumn{6}{|c|}{ Previous prolapse surgery (no of women): } \\
\hline \multicolumn{2}{|l|}{ Manchester plasty } & 33 & $52 \%$ & 40 & $59 \%$ \\
\hline \multicolumn{2}{|l|}{ Anterior colporrhaphy } & 17 & $27 \%$ & 15 & $22 \%$ \\
\hline \multicolumn{2}{|l|}{ Posterior colporrhaphy } & 7 & $11 \%$ & 9 & $13 \%$ \\
\hline \multicolumn{2}{|c|}{ Anterior and posterior colporrhaphy } & 7 & $11 \%$ & 4 & $6 \%$ \\
\hline \multicolumn{2}{|c|}{ Chronic respiratory disease (no. of women) ${ }^{*}$} & 7 & $11 \%$ & 8 & $12 \%$ \\
\hline \multicolumn{2}{|c|}{ Duration of POP symptoms $>2$ year (no. of women) * } & 31 & $57 \%$ & 32 & $53 \%$ \\
\hline$P O P-Q$ & point $\mathrm{Ba}(\mathrm{cm})$ & 0.25 & $-3-5$ & 0.00 & $-3-7$ \\
\hline$P O P-Q$ & point $\mathrm{Bp}(\mathrm{cm})$ & -1.00 & $-3-8$ & -1.75 & $-3-7$ \\
\hline \multirow[t]{3}{*}{ POP-Q anterior compartment: } & Stage $0-1$ & 12 & $19 \%$ & 18 & $26 \%$ \\
\hline & Stage 2 & 32 & $50 \%$ & 36 & $53 \%$ \\
\hline & Stage 3 & 20 & $31 \%$ & 14 & $21 \%$ \\
\hline \multirow[t]{3}{*}{ POP-Q posterior compartment: } & Stage $0-1$ & 27 & $42 \%$ & 38 & $56 \%$ \\
\hline & Stage 2 & 23 & $36 \%$ & 23 & $34 \%$ \\
\hline & Stage 3 & 14 & $22 \%$ & 7 & $10 \%$ \\
\hline \multirow[t]{2}{*}{ Overall POP-Q stage } & Stage 2 & 31 & $48 \%$ & 41 & $60 \%$ \\
\hline & Stage 3 & 33 & $52 \%$ & 27 & $40 \%$ \\
\hline
\end{tabular}

Figures indicate median and range or number and $\%$.

* Information was not available from all women. The per cents represent the proportion of those with available information.

No significant differences were found between the groups in any of the baseline characteristics. 
Table 2. Per- and postoperative data.

\begin{tabular}{|c|c|c|c|c|c|}
\hline \multirow{2}{*}{ Mode of anesthesia: } & \multicolumn{2}{|c|}{$\begin{array}{c}\text { Conventional colporrhaphy } \\
\text { group } \\
n=64\end{array}$} & \multicolumn{2}{|c|}{$\begin{array}{c}\text { Pelvicol }{ }^{\mathrm{TM}} \text { implant } \\
\text { group } \\
n=68\end{array}$} & \multirow[t]{2}{*}{$\mathrm{p}$-value } \\
\hline & & & & & \\
\hline General anesthesia & 22 & $34 \%$ & 23 & $34 \%$ & \\
\hline Spinal anesthesia & 42 & $66 \%$ & 43 & $63 \%$ & $0.384 \#$ \\
\hline Local anesthesia & 0 & $0 \%$ & 2 & $3 \%$ & \\
\hline \multicolumn{6}{|l|}{ Site of prolapse surgery: } \\
\hline Anterior compartment & 26 & $41 \%$ & 36 & $53 \%$ & \\
\hline Posterior compartment & 20 & $31 \%$ & 21 & $31 \%$ & $0.201^{\#}$ \\
\hline Ant. and post. compartment & 18 & $28 \%$ & 11 & $16 \%$ & \\
\hline Levator ani muscle plication & 7 & $11 \%$ & 6 & $9 \%$ & $0.908^{\prime \prime}$ \\
\hline Perineoplasty & 18 & $29 \%$ & 14 & $21 \%$ & $0.390 \#$ \\
\hline Concomitant vaginal hysterectomy * & 12 & $30 \%$ & 4 & $11 \%$ & $0.045^{\dagger}$ \\
\hline Concomitant vaginopexy ${ }^{* *}$ & 11 & $17 \%$ & 7 & $10 \%$ & $0.348^{\prime \prime}$ \\
\hline Concomitant surgery for SUI & 2 & $3 \%$ & 5 & $7 \%$ & $0.443^{\dagger}$ \\
\hline Per-operative bleeding volume $(\mathrm{mL})$ & 50 & $0-500$ & 50 & $0-100$ & $0.182^{¥}$ \\
\hline Transurethral catheter (days) & 1.0 & $0-3$ & 1.0 & $0-7$ & $0.802^{¥}$ \\
\hline Time in hospital (days) & 2.0 & $0-5$ & 2.0 & $0-6$ & $0.610^{¥}$ \\
\hline$P O P-Q$ at 3.month follow-up: & $n=64$ & & $n=68$ & & \\
\hline Point $\mathrm{Ba}(\mathrm{cm})$ & -2.0 & $-3-1$ & -1.5 & $-3-2.5$ & $0.395^{¥}$ \\
\hline Point Bp (cm) & -2.5 & $-3-1$ & -2.3 & $-3-4$ & $0.732^{¥}$ \\
\hline$P O P-Q$ at 3-year follow up: & $n=61$ & & $n=65$ & & \\
\hline Point $\mathrm{Ba}(\mathrm{cm})$ & -1.0 & $-3-3$ & -1.5 & $-3-5$ & $0.996^{¥}$ \\
\hline Point Bp (cm) & -2.0 & $-3-2$ & -2.5 & $-3-4$ & $0.220^{¥}$ \\
\hline
\end{tabular}

Figures indicate number and \% or median and range. SUI $=$ stress urinary incontinence * Percent of those who had a uterus. ** Sacrouterine or sacrospinous ligament fixation.

${ }^{\#}$ Yates' corrected $\chi_{\mathrm{df}=2}^{2}$; ${ }^{\# \#}$ Yates' corrected $\chi_{\mathrm{df}=1}^{2} ;{ }^{\dagger}$ Fishers' exact test; ${ }^{*}$ Mann Whitney Utest. 
Table 3. Recurrence rates three months and three years following prolapse surgery with conventional colporrhaphy (the Conventional Colporrhaphy Group (CCG)) or implant with Pelvicol $^{\mathrm{TM}}$ (the Pelvicol ${ }^{\mathrm{TM}}$ Group (PG)).

\begin{tabular}{rllll} 
& $\begin{array}{c}\text { CCG } \\
\text { (proportiont) }\end{array}$ & $\begin{array}{c}\text { PG } \\
\left.\text { (proportion }{ }^{\dagger}\right)\end{array}$ & OR $(95 \% \mathrm{Cl})$ & Adjusted OR $(95 \% \mathrm{Cl})^{*}$ \\
\hline 3-month follow-up & & & & \\
$\mathrm{Ba} \geq-1 \mathrm{~cm}$ & $39 \%(17 / 44)$ & $57 \%(27 / 47)$ & $2.14(0.93-4.96)$ & $2.53(1.03-6.25)$ \\
$\mathrm{Bp} \geq-1 \mathrm{~cm}$ & $26 \%(10 / 38)$ & $16 \%(5 / 32)$ & $0.52(0.16-1.72)$ & $0.40(0.11-1.53)$ \\
3-year follow-up & & & & \\
$\mathrm{Ba} \geq-1 \mathrm{~cm}$ & $57 \%(24 / 42)$ & $62 \%(28 / 45)$ & $1.24(0.52-2.91)$ & $1.41(0.57-3.45)$ \\
$\mathrm{Bp} \geq-1 \mathrm{~cm}$ & $40 \%(14 / 35)$ & $17 \%(5 / 30)$ & $0.30(0.09-0.97)$ & $0.43(0.12-1.56)$ \\
\hline
\end{tabular}

$\dagger$ Number of recurrences/the number of women having operation in the compartment

* Adjusted for age, parity, BMI, hysterectomy and preoperative POP stage. 


\section{Appendix}

Besides the authors the $\underline{R} e c u r r e n t ~ \underline{P} e l v i c$ Organ Prolapse (RPOP) - Pelvicol Study Group consisted of:

Jonas Gunnarsson, MD, Sahlgrenska University Hospital, Gothenburg; Eva Uustal Fornell, MD, PhD, University Hospital, Linköping; Jan Leman, MD, East Hospital, Gothenburg; Kristina Crafoord, MD, PhD, University Hospital, Örebro; Tanja Konstantinova, MD, Vrinnevi Hospital, Norrköping. Per Olof Andersson, MD, Norra Älvsborg County Hospital, Trollhättan; Margaretha Åkeson, MD, PhD, Southern Älvsborg Hospital, Borås; Gunnar Paulsson, MD, Skaraborg Hospital, Skövde; Åsa Magnusson, MD, Varberg Hospital, Varberg. 